\title{
A Study on the Relationship between College Students' Boredom Tendency and Attribution Style as well as Achievement Motivation
}

\author{
Shunqin Yan $^{1}$ \\ ${ }^{1}$ School of education, China West Normal University, nanchong, China \\ Correspondence: Shunqin Yan, School of education, China West Normal University, nanchong, China, ON., No 1 \\ Shi Da Road, Nanchong City, Sichuan Province, China. E-mail: yanshunqin@126.com
}

Received: June 12, 2016

Accepted: July 25, 2016

Online Published: August 5, 2016

doi:10.5430/ijhe.v5n3p117

URL: http://dx.doi.org/10.5430/ijhe.v5n3p117

\begin{abstract}
Aim: This thesis discusses the relationship between college students' boredom tendency and attribution style as well as achievement motivation. Method: The author uses scale assessment on college students of boredom tendency scale, the inner-control scale, internality-powerful others scale and chance scale draw up by Leveson, as well as achievement motivation scale. Results: 1) There is no significant differences in sex on the boredom tendency of college students; in grade level, a comparatively significant difference exists between the total scores of tension, binding force and boredom tendency. 2) The total score of boredom tendency has significant negative correlation with that of achievement motivation $(\mathrm{r}=-0.509, \mathrm{p}<0.01)$, has significant negative correlation with the success-wish dimension $(\mathrm{r}=-0.284, \mathrm{p}<0.05)$, has significant positive correlation with the failure-fear dimension $(\mathrm{r}=0.505, \mathrm{p}<0.01)$, has negative correlation with the inner-control dimension $(\mathrm{r}=-0.133, \mathrm{p}<0.05)$, has positive correlation with the chance dimension $(\mathrm{r}=0.406, \mathrm{p}<0.01)$, and has significant positive correlation with internality-powerful others dimension $(\mathrm{r}=0.373, \mathrm{p}<0.01) .3)$ The boredom tendency has mediating effect on achievement motivation and attribution style. Conclusion: The boredom tendency is closely related to the attribution style and achievement motivation, and plays a partial mediating role in the relationship between attribution style and achievement motivation.
\end{abstract}

Keywords: College students, Boredom tendency, Achievement motivation, Attribution style, Mediating effect

\section{Introduction}

Boredom, considered as one of the plagues in modern society, is a widespread and common emotional experience (R.Pekrun, T.Goetzb, L.M.Daniels et al., 2010). However, boredom can also develop into a chronic, widespread pressure source, the essence of which is an idiosyncratic boredom, called boredom tendency. Boredom tendency refers to the emotional reaction to boredom in relatively lasting personality characteristics and the stable individual differences of behavior (Zhong Yongru, Huang Shihua, Xiong Songbin, 2014). As a particular personality showing emotion, boredom tendency may be closely related to attribution style, one of the important elements affecting the production of emotion. Research shows, attribution style has a directly negative prediction function on the sense of boredom, and the promotion of inner-control can effectively reduce the boredom tendency (Lou Xia, 2012). At present, there is few relevant research materials for the research on the relationship between the boredom tendency and achievement motivation.

Then what is the relationship between boredom tendency and attribution style as well as achievement motivation? We can assume that individuals with high achievement motivation will voluntarily look for stimulus. Since the external stimulus is enough to satisfy their inner needs, they don't easily feel bored; whereas individuals with low achievement motivation, feel the opposite. Similarly, students with internal attribution tendency are more likely to do things to change themselves, thus they don't easily feel bored; while students with external attribution tendency, the opposite. The research on the relationship between boredom tendency and attribution style as well as achievement motivation provides debugging countermeasures for the precaution and remission of the rising of college students' boredom tendency. 


\section{Objects and Methods}

\subsection{Objects}

In this research, altogether 600 testees are chosen from colleges in Chengdu and Nanchong for questionnaire survey. 530 questionnaire papers (89\%) are valid, among which 121students are boys, 409 are girls; 91 students are freshmen, 97 are sophomores, 173 are juniors, and 169 are seniors; and the age of them are 16 to 24 (20.78 \pm 1.29$)$.

\subsection{Research Tools}

1) College Students Boredom Tendency Scale (Huang Shihua, Li Dongling, Zhang Wei, 2010).

The research uses "college students boredom tendency scale" by Huang Shihua, a professor of Guangzhou University of Chinese Medicine. The scale altogether has 30 question items, including six dimensions: monotonicity, loneliness, self-control, creativity, tension and restraint. Seven points scoring mode is used, from complete inconformity to complete conformity (1-7). The higher the score is, the stronger the sense of boredom is. The acoefficient of the questionnaire is 0.87 ; and the test-retest reliability is 0.80 .

2) Inner-control, Internality-powerful others and Chance Scale (Wang Deqiang, 2007).

The research uses the Inner-control, the Internality-powerful others and Chance Scale (IPC) by Leveson, including three parts: the Inner-control scale, the Internality-powerful others scale and Chance Scale, which are independent from each other, and are labeled as I, P, C respectively. The three scales respectively include 8 question items, which can be independently used. With five points scoring mode, the scale has good reliability and validity according to the test.

3) Achievement Motivation Scale (Liang Liping, Chao Xiangming, 1998).

The research uses Achievement Motivation Scale (AMS) by Gjesme.Tand Nygard.R, with 30 question items, including success-wish and failure-avoidance dimensions. The acoefficient are 0.86 and 0.84 respectively. The final score of the scale is the score of success-wish minus the score of failure-avoidance.

\section{Results and Analysis}

\subsection{Statistics of the Descriptiveness and the Differentiation of Boredom Tendency}

There is no significant difference between male and female college students in the total score of boredom. The significant difference only exists in the sense of loneliness and tension dimensions, in which the score of male students is significantly higher than that of female students in the loneliness dimension $(t=2.082, p<0.05)$, the score of female students is higher than that of male students in the tension dimension $(t=-2.196, p<0.05)$. In grade level, there is significant difference between male and female students in the sense of tension, constraint and boredom tendency.

\subsection{The Relevant Analysis of Boredom Tendency and Attribution Style as well as Achievement Motivation}

The total score of boredom tendency is significantly related to that of achievement motivation, success-wish and failure-fear, as well as to that of inner-control, chance and internality-powerful others, in which, the total scores of achievement motivation, success-wish and inner-control dimension are negatively correlated with boredom tendency; failure-fear, chance and internality-powerful others are positively correlated with boredom tendency. This shows that boredom tendency is closely related to achievement motivation and attribution style. See Table 1.

Table 1. The Correlation between Boredom Tendency and Achievement Motivation as well as Attribution Style

\begin{tabular}{lccccccccc}
\hline Item & Monotonicity & $\begin{array}{l}\text { Loneliness } \\
\text { F1 }\end{array}$ & $\begin{array}{l}\text { Tension } \\
\text { F5 }\end{array}$ & $\begin{array}{l}\text { Restraint } \\
\text { F6 }\end{array}$ & $\begin{array}{l}\text { External } \\
\text { Stimulus } \\
\text { G1 }\end{array}$ & $\begin{array}{l}\text { Self-control } \\
\text { F3 }\end{array}$ & $\begin{array}{l}\text { Creativity } \\
\text { F4 }\end{array}$ & $\begin{array}{l}\text { Internal } \\
\text { Stimulus } \\
\text { G2 }\end{array}$ & $\begin{array}{l}\text { Boredom } \\
\text { TP }\end{array}$ \\
\hline $\begin{array}{l}\text { Achievement } \\
\text { Motivation TP }\end{array}$ & $-0.33^{* * *}$ & $-0.296^{* * *}$ & $-0.336^{* * *}$ & $-0.236^{* * *}$ & $-0.412^{* * *}$ & $-0.344^{* * *}$ & $-0.352^{* * *}$ & $-0.401^{* * *}$ & $-0.509^{* * *}$ \\
Success-wish & -0.103 & -0.067 & $-0.118^{*}$ & -0.007 & $-0.108^{*}$ & $-0.379^{* * *}$ & $-0.327^{* * *}$ & $-0.420^{* * *}$ & $-0.284^{* * *}$ \\
Failure-fear & $0.378^{* * *}$ & $0.361^{* * *}$ & $0.374^{* * *}$ & $0.328^{* * *}$ & $0.489^{* * *}$ & $0.160^{* * *}$ & $0.216^{* * *}$ & $0.206^{* * *}$ & $0.505^{* * *}$ \\
Inner-control & -0.080 & $-0.133^{*}$ & 0.048 & 0.080 & -0.065 & $-0.236^{* * *}$ & -0.055 & $-0.206^{* * *}$ & $-0.133^{*}$ \\
$\begin{array}{l}\text { Chance } \\
\text { Internality-powerful }\end{array}$ & $0.295^{* * *}$ & $0.340^{* * *}$ & $0.299^{* * *}$ & $0.283^{* * *}$ & $0.409^{* * *}$ & $0.141^{* *}$ & 0.044 & $0.128^{*}$ & $0.406^{* * *}$ \\
others & $0.260^{* * *}$ & $0.340^{* * *}$ & $0.215^{* * *}$ & $0.311^{* * *}$ & $0.377^{* * *}$ & $0.108^{*}$ & 0.073 & $0.112^{*}$ & $0.373^{* * *}$ \\
\hline
\end{tabular}

Note: $* \mathrm{P}<0.05, * * \mathrm{P}<0.01, * * * \mathrm{P}<0.001$ 


\subsection{The Mediating Effect of Boredom Tendency on Achievement Motivation and Attribution Style}

The method proposed by Baron and Kenny is used to test and comment on mediating effect (Baron R M, Kenny D A, 1986). The standard to measure the existence of mediating effect is as follow: In the first regression equation, the independent variable significantly affects the mediating variable; in the second regression equation, the independent variable significantly affects the dependent variable; in the third regression equation, the mediating variable significantly affects the dependent variable, and meanwhile, the effect of independent variable on dependent variable grows weaker. Under the condition that the three factors exist at the same time, if, in the third regression equation, the Beta value of the effect of the independent variable on the dependent variable is still significant, it is partial mediation. In this research, the value of the score of chance is still significant $(\beta=-0.149, p=0.003 * *)$ after the introduction of boredom tendency. Therefore, the boredom tendency has a partial mediating effect on attribution style and achievement motivation. The mediating effect accounts for $16.6 \%$ of the total effect.

\section{Discussion}

\subsection{Discussion on the Results of the Statistics of Descriptiveness and the Analysis of Differentiation}

There is no significant difference between male and female college students in the total score of boredom tendency. However, in the sense of loneliness, the score of male students is higher than that of female students, and in the sense of tension, the score of female students is higher than that of male students. This shows that most of the students can arrange their time well. Nevertheless, since different sex are granted different duty by culture, males are supposed to shoulder more responsibility in social life and have to accomplish many things independently, otherwise, they are considered weak. Therefore, males are supposed to develop independently since childhood, so they may more easily feel lonely. In contrast to that, females are more inclined to do team work, and because of that, females are more easily affected by environment and have the sense of tension by the influence of others.

In grade level, the variance analysis shows that there is significant difference between the scores of tension, restraint, and boredom tendency, and the difference lies mainly between the first, the third and the fourth years. The possible reason of this is that with the great mental release after 12 years' hard study as well as with less heavy academic pressure in college than that in high school, and the loneliness of homesickness, the freshmen usually have difficulty in adjusting, and they are, because of this, always at a loss and idling about without knowing what to do. And the long-standing state of this may cause them to feel bored. On the other hand, students in the third and the fourth years have completely adapted to college life, and are faced with the pressure of further education or that of graduation and employment. Therefore, the total score of their boredom tendency may be even lower.

4.2 Discussion on the Correlation between Boredom Tendency and Achievement Motivation as well as Attribution Style

\section{1) Correlation Between Boredom Tendency and Achievement Motivation}

The table of correlation between boredom tendency and achievement motivation shows all factors of boredom tendency are almost correlated with achievement motivation. There is significant positive correlation between success-wish and the total score of boredom tendency. The greater the wish of success is, the easier it is for one to feel bored. This is possibly because success needs much effort and boring hard work, and meanwhile, there is significant negative correlation between success-wish and self-control, creativity, as well as internal stimulus. And the more lack of inspiration, self-control and inner needs an individual has, the more wish he has for success to try to prove his ability. However, there is significant positive correlation between the failure-fear and all factors of boredom, possibly because the more fear for failure one feels, the less he dares to try, and thus he abandons some regulations and efforts for success, leaving himself in a state of idling about. Moreover, this kind of avoidance mode can also affect interpersonal communication, so it may also cause him to feel more lonely. On the other hand, there is significant negative correlation between achievement motivation and all factors of boredom, possibly because individuals with high achievement motivation will set for themselves a series of plans and tasks to achieve the goals that they think are great. Thus they feel life is rich and valuable, and do not feel bored.

\section{2) Correlation Between Boredom Tendency and Attribution Style}

In the correlation between boredom tendency and attribution style, the inner-control has significant negative correlation with self-control and internal stimulus, and has comparatively significant negative correlation with the total score of boredom and sense of loneliness. This shows individuals with high self-control may less easily feel lonely. As for Chance, almost all the factors of boredom tendency have significant positive correlation with it. This shows when an individual takes his success as a luck, he may not consider the activity itself to be indispensable, and may feel less importance of the role he plays in the success as well as less sense of great achievement and happiness. 
The Internality-powerful others has significant positive correlation with nearly all the factors of boredom, possibly because when an individual feels that all his activities are controlled by others, he may have lower inner-motivation, and may feel difficult to find the activities that he finds meaningful, and thus feels bored.

\subsection{Analysis of the Mediating Effect of Boredom Tendency on Attribution Style and Achievement Motivation}

Analysis of the mediating effect shows that the total score of boredom tendency has partial mediating effect on chance and achievement motivation. In chance and achievement motivation, the latter can not only be affected by chance itself, but also be affected by the sense of boredom. Individuals strongly affected by chance hold that they can hardly control their life, for the good or bad of life is more affected by fate or luck. Therefore, they can hardly feel the sense of satisfaction and achievement brought by life, and fall in a kind of agitated and anxious state in which they feel life is valueless. This state is the sense of boredom. In previous research, Fahlaman also points out that individuals with strong sense of boredom do not know what they really need, lack the goal of life and find little meaning of it, so they have weak self-determination (Fahlman S A,Mercer K B,Gaskovski P, 2009). Therefore, the boredom tendency plays a very importance role in attribution style and achievement motivation.

\section{References}

Baron R M,Kenny D A. (1986). The Moderator-mediator variable distinction in social psychological research: Conceptual,strategic, and statistical considerations. Journal of Personality and Social Psychology, 51, 1173-1182. http://dx.doi.org/10.1037/0022-3514.51.6.1173

Fahlman S A, Mercer K B,Gaskovski P. (2009). Does a lack of life meaning cause boredom? Results from psychometric, longitudinal, and experimental analyses. Journal of Social and clinical psychology, 28, 307-312. http://dx.doi.org/10.1521/jscp.2009.28.3.307

Huang Shihua, Li Dongling, Zhang Wei. (2010). The Preliminary Compilation of Questionnaires on Boredom Tendency of College Students. Mental Development and Education, 3, 34-39.

Liang Liping, Chao Xiangming. (1998). Research on Evaluation of College Students' Achievement Motivation and Achievement Behaviors. Psychological Science, 21(4), 377-378.

Lou Xia. (2012). Research on the Relationship between the locus of control, Leisure Motivation and Sense of Boredom of College Students. Chongqing: Southwest University.

R.Pekrun, T.Goetzb, L.M.Daniels et al. (2010). Boredom in Achievement Settings: Exploring Control Value Antecedents and Performance Outcomes of a Neglected Emotion. Journal of Educational Psychology, 102(3), 531-549. http://dx.doi.org/10.1037/a0019243

Wang Deqiang. (2007). Research on the Relationship Between Cognitive Evaluation, Locus of Control, Social Support and the Employment Pressure of College Students. Journal of Health Psychology of China, 15(12), 1142-1144.

Zhong Yongru, Huang Shihua, Xiong Songbin. (2014). The Boredom Tendency of College Students and Mental Health. Journal of Health Psychology of China, 22(7), 1086-1090. 